\title{
Change in Value of Effective Anisotropy of FeCoB Amorphous Alloys, Depending on Chemical Composition
}

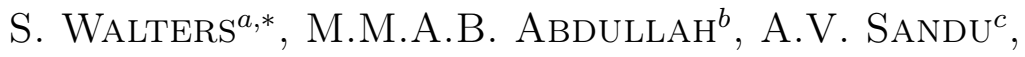 \\ S. Garus ${ }^{d}$, M.A.A. Mohd SAleh ${ }^{b}$, \\ D.S. Che HALin ${ }^{b}$ AND F.F. ZAINAL ${ }^{b}$ \\ ${ }^{a}$ Advanced Engineering Centre, University of Brighton, BN2 4GJ, Brighton, United Kingdom \\ ${ }^{b}$ Centre of Excellence Geopolymer and Green Technology (CEGeoGTech), \\ Universiti Malaysia Perlis (UniMAP), 01000 Kangar, Perlis, Malaysia \\ ${ }^{c}$ Gheorghe Asachi Technical University of Iasi, \\ Faculty of Materials Science and Engineering, Iasi, Romania \\ ${ }^{d}$ Czȩstochowa University of Technology, al. Armii Krajowej 19, 42-200 Czȩstochowa \\ Doi: 10.12693/APhysPolA.139.568 \\ *e-mail: S.D.Walters@brighton.ac.uk
}

\begin{abstract}
The magnetisation process of amorphous materials is similar to that of crystalline materials and consists of four stages. Each step influences the formation of the primary magnetisation curve. By using measurements in the "easy," "intermediate" and "difficult" magnetisation directions, the primary magnetisation curves are obtained, on the basis of which the value of effective anisotropy can be determined. This paper presents the results of tests that were carried out on two amorphous alloys that are based on an Fe matrix. The value of effective anisotropy was related to the spin-wave stiffness parameter.
\end{abstract}

topics: effective anisotropy, amorphous alloys, primary magnetisation curve, saturation magnetisation

\section{Introduction}

Magnetic materials are an indispensable part of our current life. It is hard to imagine life without the electronics around us. Looking for newer technological solutions is ongoing, state-of-the-art materials are being used, and the goal of all this is to get the systems with the lowest energy requirements. Electrical equipment absorbs large amounts of electricity depending on the intensity of its use. By reducing the amount of losses per magnetization and by reducing the effective anisotropy field, a material with a reduced energy demand can be obtained in relation to its precursors [1-3].

Such properties are characteristic of rapidlycooled FeB alloys [4-8]. In the case of crystalline materials, it has been found that their magnetization occurs much more easily in certain designated directions described crystallographically [9]. These directions are called easy magnetization directions and are closely related to magnetocrystalline anisotropy $[10,11]$. In practice, this means that the smallest work is needed to achieve a state of magnetic saturation in this direction. For other directions, the work is greater. The difference between working in a non-easy and easy direction is called magneto-crystalline anisotropy. When it comes to describing this energy for crystalline systems, it is simple. In general, it is an orbital movement of electrons within a crystalline network, which must reflect the symmetry of the network. Overlapping the wave functions of electrons associated with other atoms is easier for individual orbit orientations and more difficult for others. This means that there are positions that are more energy advantageous than the other ones.

As regards the description of amorphous materials in terms of their anisotropy, this is hampered by the lack of crystalline lattice in their volume. It would seem that in this case these materials are isotropic. However, they exhibit a number of factors described as anisotropy. The sum of these anisotropy is the so-called effective anisotropy. In amorphous materials, there is anisotropy mainly related with stress, one-way, magnethostatic, induced and associated with the heterogeneity of the structure. The latter is called the local anisotropy, which is associated with different sample areas and arrangement of individual pairs of atoms and interactions between them [12-16].

This work presents the results of structure tests and magnetic properties for amorphous alloys based on the FeCoB matrix. 


\section{Materials and methods}

Using the radiation cooling method, amorphous samples were produced. The first stage of the production was the preparation of alloy ingredients and their weighing according to the recipe. Weighed were $10 \mathrm{~g}$ portions of ingredients of purity: $\mathrm{Fe}-99.98 \%$, Co - 99.98\%. Boron was added in the form of the FeB alloy with a chemical composition $\mathrm{Fe}_{54.4} \mathrm{~B}_{44.6}$. The prepared portions of $10 \mathrm{~g}$ were melted in an arc furnace in an inert gas atmosphere. Cleaning of working atmosphere was twostage: twice a high vacuum was obtained in the working chamber and flushed with argon. Melting of the components was preceded by the melting of pure titanium, which served as an absorbent of the remaining impurities, mainly oxygen. Alloying ingredients were melted four times on each side to mix them well. Finally, ingots were obtained, which were re-weighed. Weight loss was negligible. Such ingots were cleaned of impurities with the help of friction materials and an ultrasonic cleaner.

Purified ingots were divided into smaller portions by the use of mechanical guillotine for this purpose. Subsequently, ingot pieces were placed in a quartz tube with a diameter of $12 \mathrm{~mm}$ and an outlet hole of $1.5 \mathrm{~mm}$. The tube was connected to a pressure valve in a system with a cylinder filled with argon. Melting of the ingot piece was carried out using a high frequency generator. When eddy currents affected the sample, the valve was released and argon pressure pressed the liquid alloy into the watercooled copper mold.

The whole process took place in a chamber within protective gas atmosphere. Resulting samples were shaped like rods of $1 \mathrm{~mm}$ diameter and $\approx 20 \mathrm{~mm}$ in length. The structure was tested using a BRUKER ADVANCE 8 X-ray diffractometer equipped with a cobalt lamp and working in Bragg Brentano geometry. Samples were crushed in an agate mortar in toluene and placed inside the measuring system. Measurement was made in the $2 \theta$ angle range from $30^{\circ}$ to $100^{\circ}$ with an exposure time of $7 \mathrm{~s}$ per measuring step of $0.02^{\circ}$. Measurements were made at room temperature.

Magnetic properties were tested using a LAKESHORE vibrating magnetometer model 7307 operating up to a maximum magnetic field intensity of 2 T. Static magnetic hysteresis loops and primary magnetization curves in three highlighted directions determining the main magnetization directions were measured.

\section{Results}

Figure 1 illustrates tests performed with the X-ray diffractometer. Resulting X-ray diffractograms are classic in terms of amorphous materials. Only a single wide maximum called the amorphous hall can be distinguished in these X-ray

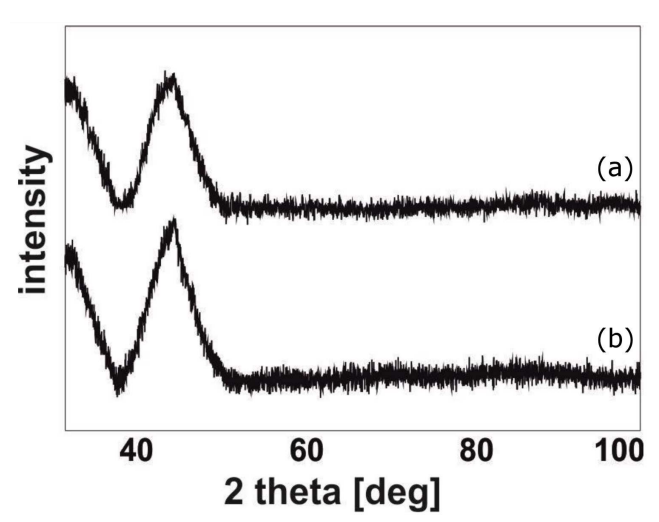

Fig. 1. X-ray diffraction patterns for the alloy samples (a) $\mathrm{Fe}_{62} \mathrm{Co}_{9} \mathrm{Y}_{8} \mathrm{~W}_{1} \mathrm{~B}_{20}$, $\mathrm{Fe}_{63} \mathrm{Co}_{8} \mathrm{Y}_{8} \mathrm{~W}_{1} \mathrm{~B}_{20}$.

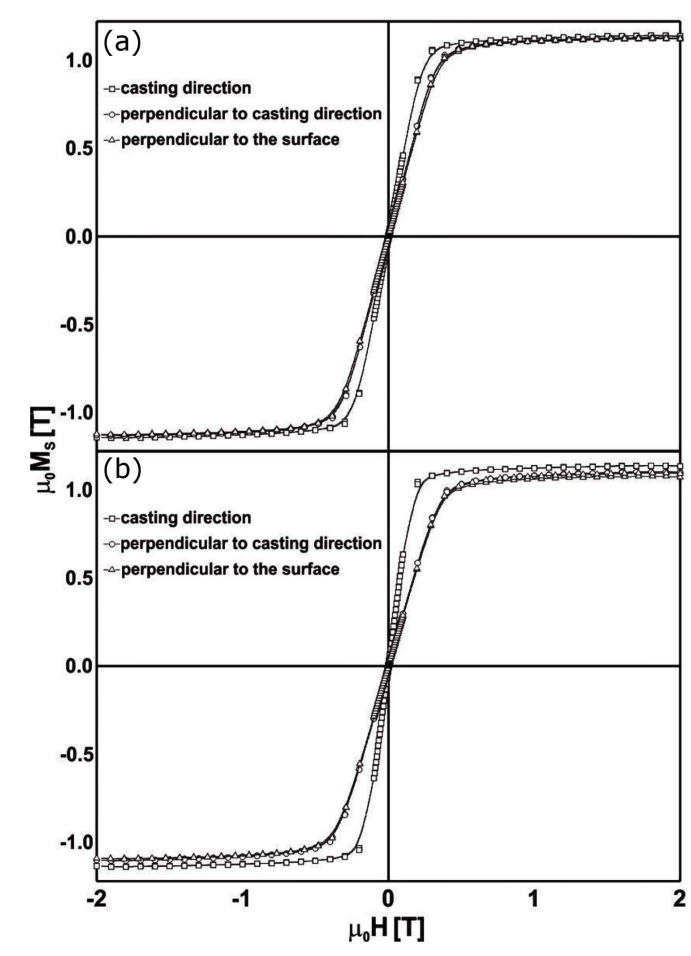

Fig. 2. Static magnetic hysteresis loops for tested amorphous alloys: (a) $\mathrm{Fe}_{62} \mathrm{Cog}_{9} 8 \mathrm{~W}_{1} \mathrm{~B}_{20}$, (b) $\mathrm{Fe}_{63} \mathrm{Co}_{8 Y}{ }_{8} \mathrm{~W}_{1} \mathrm{~B}_{20}$.

diffraction images. The rest of the diffractograms are low-intensity backgrounds. In Fig. 2, there are static magnetic hysteresis loops measured for the test alloys.

The tested samples are ferromagnets with magnetically soft properties. Both alloys have a similar saturation magnetization and coercive field values. Primary magnetization curves (measured in the three highlighted directions) are shown in Fig. 3. Based on the curves, the parameter $D_{\text {spf }}$ was calculated [17].

Table I collects the results from the obtained measurements. 


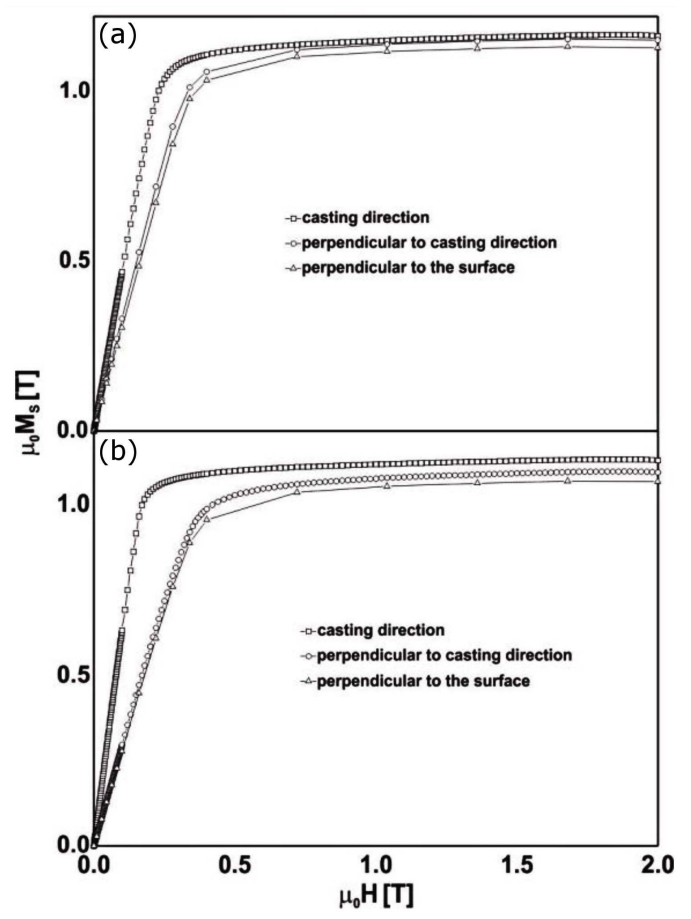

Fig. 3. Primary magnetisation curves measured in three directions 1, 2, 3 for the tested alloys (a), (b).

TABLE I

The following notation applies: $\mu_{0} M_{S}$ - the saturation magnetization [T], $H_{C}$ - the coercivity field $[\mathrm{A} / \mathrm{m}], D_{\mathrm{spf}}$ - the spin-wave stiffness parameter $\left[\mathrm{meVnm}^{2}\right], P_{1}$ - the anisotropy field in the other direction $\left[\mathrm{kJ} / \mathrm{m}^{3}\right], P_{2}$ - the anisotropy in the first direction $\left[\mathrm{kJ} / \mathrm{m}^{3}\right], P_{3}-$ the anisotropy in the third direction $\left[\mathrm{kJ} / \mathrm{m}^{3}\right]$.

\begin{tabular}{l|c|c|c|c|c|c}
\hline \hline & $\mu_{0} M_{S}$ & $H_{C}$ & $D_{\text {spf }}$ & $P_{1}$ & $P_{2}$ & $P_{3}$ \\
\hline $\mathrm{Fe}_{48} \mathrm{Co}_{24} \mathrm{Y}_{8} \mathrm{~B}_{20}$ & 1.17 & 61 & 48 & 149 & 195 & 199 \\
$\mathrm{Fe}_{43} \mathrm{Co}_{29} \mathrm{Y}_{8} \mathrm{~B}_{20}$ & 1.14 & 47 & 49 & 110 & 199 & 200
\end{tabular}

As indicated by the data in Table I, manufactured rods definitely show anisotropy. The direction of easy magnetization is the direction along the axis of the tested bar. A material with the lowest energy of effective anisotropy showed the best magnetic soft properties, i.e., the lowest coercive field.

\section{Conclusions}

Anisotropy in amorphous materials is a factor influencing their magnetic properties depending on the direction of their magnetization, as in crystalline materials. However, it should be noted that differences between different magnetization directions are much smaller than for crystalline materials. In addition, amorphous materials can be thermally relaxed, which reduces the effective anisotropy. Additionally, there is no or residual anisotropic factor in them, which is the magnetostriction.

\section{References}

[1] B. Płoszaj, M. Nabiałek, K. Błoch, B. Koczurkiewicz, A.V. Sandu, M.M.A.B. Abdullah, A. Kalwik, B. Jeż, Acta Phys. Pol. A 138, 221 (2020).

[2] Y. Jin, Y. Chao, F. Liu, J. Wang, M. Sun, J. Magn. Magn. Mater. 468, 181 (2018).

[3] I. Ibarrondo, J. Degauque, Vacuum 53, 75 (1999).

[4] M. Nabiałek, B. Jeż, K. Błoch, J. Gondro, K. Jeż, A.V. Sandu, P. Pietrusiewicz, J. Alloys Compd. 820, 153420 (2020).

[5] K. Jeż, B. Jeż, P. Pietrusiewicz, Rev. de Chim. 70, 3158 (2019).

[6] X. Li, Z. Shi, T. Zhang, J. Alloys Compd. 784, 1139 (2019).

[7] F. Wang, A. Inoue, Y. Han, F. Kong, S. Zhu, E. Shalaan, F. Al-Marzouki, A. Obaid, J. Alloys Compd. 711, 132 (2017).

[8] Y. Geng, Y. Wang, Z. Wang, J. Qiang, H. Wang, C. Dong, O. Tegus, Mater. Design 106, 69 (2016).

[9] E. C. Stoner, E.P. Wohlfarth, Phil. Trans. R. Soc. London A 240, 599 (1948).

[10] L. Zhu, S.S. Jiang, Z.Z. Yang, G.B. Han, S.S. Yan, Y.G. Wang, J. Magn. Magn. Mater. 519, 167513 (2021).

[11] T. Suetsuna, H. Kinouchi, N. Sanada, J. Magn. Magn. Mater. 519, 167475 (2021).

[12] J. Olszewski, J. Zbroszczyk, M. Hasiak et al., J. Rare Earths 27, 680 (2009).

[13] M. Nabiałek, J. Zbroszczyk, J. Olszewski, M. Hasiak, W. Ciurzyńska, K. Sobczyk, J. Świerczek, J. Kaleta, A. Łukiewska, J. Magn. Magn. Mater. 320, e787 (2008).

[14] K. Gruszka, M. Nabiałek, K. Błoch, S. Walters, Int. J. Mater. Res. 106, 689 (2015).

[15] J. Gondro, K. Błoch, M. Nabiałek, S. Garus, Mater. Tehnol. 50, 55 (2016).

[16] B. Jeż, J. Wysłocki, S. Walters, P. Postawa, M. Nabiałek, Materials 13, 1367 (2020).

[17] K. Błoch, Rev. de Chim. 69, 982 (2018). 